\title{
Association between IL-1beta and cardiovascular disease risk in patients with newly diagnosed, drug-naïve type 2 diabetes mellitus: a cross-sectional study
}

\author{
Kyong Hye Joung ${ }^{1 \#}$, Ji Min Kim ${ }^{1 \#}$, Sorim Choung ${ }^{2}$, Ju Hee Lee ${ }^{1}$, Hyun Jin Kim ${ }^{1}$, Bon Jeong Ku ${ }^{1}$ \\ ${ }^{1}$ Department of International Medicine, ${ }^{2}$ Department of Medical Science, Chungnam National University College of Medicine, Daejeon, Republic \\ of Korea \\ Contributions: (I) Conception and design: KH Joung, JM Kim, BJ Ku; (II) Administrative support: None; (III) Provision of study materials or patients: \\ KH Joung, JM Kim; (IV) Collection and assembly of data: KH Joung, JM Kim; (V) Data analysis and interpretation: All authors; (VI) Manuscript \\ writing: All authors; (VII) Final approval of manuscript: All authors. \\ \#These authors contributed equally to this work. \\ Correspondence to: Bon Jeong Ku. Department of Internal Medicine, Chungnam National University College of Medicine, Daejeon 34134, Republic \\ of Korea. Email: bonjeong@cnu.ac.kr.
}

\begin{abstract}
Background: To determine whether the pro-inflammatory cytokine interleukin (IL)-1beta, as a marker of the nucleotide binding and oligomerization domain-like receptor family pyrin domain-containing 3 (NLRP3) inflammasome activation, can be used to predict cardiovascular disease (CVD) risk in patients with newly diagnosed, drug-naïve type 2 diabetes mellitus (T2DM).

Methods: A total of 110 subjects with no history of diabetes were enrolled and divided into control subjects (non-DM group, n=52) and patients with newly diagnosed, drug-naïve T2DM (DM group, n=58).

Results: Serum IL-1beta levels were not different between the two groups. The Framingham CVD risk score (F-score) was positively correlated with the serum IL-1beta level in the DM group. Multivariate regression analyses showed that the F-score was independently associated with the serum IL-1beta level in the DM group. Patients with an intermediate to high CVD risk (F-score $\geq 10 \%$ ) also had significantly higher serum IL-1beta levels than did those with a low CVD risk (F-score $<5 \%)$. Smokers in the DM group had higher IL-1beta levels than did those in the non-DM group, regardless of the F-score.

Conclusions: These results suggest that serum IL-1beta levels might be useful as an independent risk factor predicting CVD risk in patients with newly diagnosed, drug naïve T2DM, particularly those who smoke.
\end{abstract}

Keywords: Cardiovascular disease risk; IL-1beta; type 2 diabetes mellitus

Submitted Nov 13, 2019. Accepted for publication Dec 27, 2019.

doi: $10.21037 /$ atm.2020.01.17

View this article at: http://dx.doi.org/10.21037/atm.2020.01.17

\section{Introduction}

The relationship between type 2 diabetes mellitus (T2DM) and cardiovascular disease (CVD) has been recognized for many years. However, the pathophysiology of CVD in patients with T2DM is not fully understood. Some studies have suggested that mortality from CVD in patients with T2DM is related to the degree of hyperglycemia, particularly the glycosylated hemoglobin $\left(\mathrm{HbAl}_{\mathrm{C}}\right)$ level
(1-5), but not to other CVD risk factors, such as male sex, current smoking, high-density lipoprotein (HDL) cholesterol level, and systolic blood pressure (SBP) (3). On the other hand, other studies have demonstrated that CVD risk in patients with T2DM varies widely and depends more on existing vascular disease, proteinuria or renal disease, and lowering blood lipid levels and blood pressure than on glucose control (6-8). 


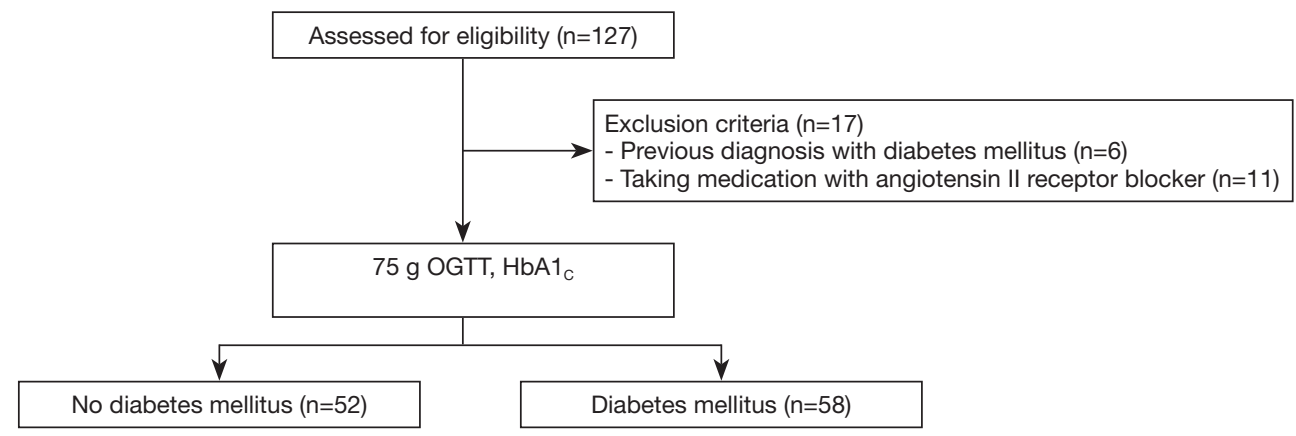

Figure 1 Flow chart of the inclusion and exclusion criteria in this study. A total of 120 participants enrolled in this study after 17 of 127 recruits were excluded. A total of 58 participants were classified as diabetes mellitus by examination of $75 \mathrm{~g} \mathrm{OGTT} \mathrm{and} \mathrm{HbA1} \mathrm{C}$. OGTT, oral glucose tolerance; $\mathrm{HbA1}_{\mathrm{C}}$, hemoglobin A1c.

CVD risk is increased two- to four-fold in patients with T2DM compared with nondiabetic subjects and is the leading cause of death in patients with T2DM $(9,10)$. Therefore, predicting CVD is very important to decrease mortality in patients with T2DM. The Framingham risk score (F-score) was developed to estimate the 10-year CVD risk, based on age, sex, total cholesterol, HDL-cholesterol, smoking, diabetes, SBP, and use of hypertensive medication $(11,12)$. Although this scoring system has been used to predict CVD risk worldwide, its accuracy is insufficient in patients with T2DM, in whom CVD develops due to various factors (13). Many studies have suggested new methods or markers to predict CVD more accurately (14-17), but these methods and markers have restricted availability.

Chronic activation of the innate immune system through the nucleotide binding and oligomerization domainlike receptor family pyrin domain-containing 3 (NLRP3) inflammasome leads to maturation and secretion of proinflammatory cytokines, such as interleukin (IL)-1beta and IL-18, and plays a critical role in the pathogenic mechanism of T2DM and CVD (18-21). In our previous study, greater activation of the NLRP3 inflammasome was detected in myeloid cells from patients with newly diagnosed, drugnaïve T2DM, and antidiabetic treatment with metformin helps modulate activation of the inflammasome (22).

However, no study has determined whether activation of the NLRP3 inflammasome and its products can predict CVD risk in patients with T2DM. Therefore, we investigated the association between CVD risk using the F-score and the serum IL-1beta level as an activation marker of the NLRP3 inflammasome in control subjects without T2DM and in patients with newly diagnosed, drug- naïve T2DM.

\section{Methods}

\section{Study population}

We presented our study flow chart in Figure 1. The inclusion criterion in this study was age 20-65 years. Exclusion criteria were history of diabetes or CVD, including stroke, ischemic heart disease, and heart failure; clinical evidence of advanced liver or renal disease; malignant disease; and use of medications, such as angiotensin II receptor blockers or statins. After a detailed clinical history, including medical treatment and CVD history, all enrolled subjects underwent $75 \mathrm{~g}$ oral glucose tolerance test (OGTT) and $\mathrm{HbAl}_{\mathrm{C}}$, and the T2DM diagnosis was based on the 2015 American Diabetes Association diagnostic criteria (23). A total of 110 subjects ( 52 healthy control subjects and 58 patients with newly diagnosed, drug naïve T2DM) with no previous diagnosis of diabetes were recruited from patients who visited the Diabetes Center at Chungnam National University Hospital for a diabetes evaluation from January 2012 to December 2014. All subjects had baseline records of age, body mass index (BMI), blood pressure (BP), smoking status and alcohol consumption. BMI $\left(\mathrm{kg} / \mathrm{m}^{2}\right)$ was calculated as weight $(\mathrm{kg}) /[\text { height }(\mathrm{m})]^{2}$. BP was measured using a calibrated sphygmomanometer after the subjects had rested for $10 \mathrm{~min}$.

\section{Biochemical analysis}

Blood samples were collected from an antecubital vein at the time of the OGTT after at least an $8 \mathrm{~h}$ overnight fast. Venous blood specimens were separated after clotting 
by centrifugation for $15 \mathrm{~min}$ at $1,000 \mathrm{~g}$. Serum samples were subsequently stored in aliquots at $-80{ }^{\circ} \mathrm{C}$. Blood chemistry and lipid profiles were measured using an automated blood chemistry analyzer (Hitachi 747; Hitachi, Tokyo, Japan). HbA1 $1_{\mathrm{C}}$ was measured by highperformance liquid chromatography (HPLC) using the National Glycohemoglobin Standardization Program and standardized to the Diabetes Control and Complications Trial assay reference (24). HPLC was performed using a certified automated analyzer (HLC-723G7 hemoglobin HPLC analyzer; Tosoh Corp., Tokyo, Japan). Insulin and C-peptide levels were measured by radioimmunoassay (Roche, Penzberg, Germany). Serum IL-1beta levels were measured using a commercially available human enzymelinked immunosorbent assay kit (BD Pharmingen, San Jose, CA, USA), according to the manufacturer's instructions.

\section{Calculations}

Homeostasis model assessment was determined using insulin resistance (HOMA-IR) and HOMA of insulin secretion (HOMA-beta) (25). HOMA-IR was calculated as basal glucose $\times$ basal insulin/405. HOMA-beta (\%), representing beta cell function, was calculated as $360 \times$ basal insulin/(basal glucose - 63). Glucose is presented in $\mathrm{mg} / \mathrm{dL}$ and insulin in $\mu \mathrm{IU} / \mathrm{mL}$ (26). The CVD risk assessment was represented by the F-score calculated using a computer program offered by NIH. Patients with F-score less than 5\% were considered to be low CVD risk. A F-score of $10 \%$ or more indicates moderate to severe CVD risk. We examined the association between F-score and IL-1beta in these two categories. We also divided the lower and higher IL-1beta group according to IL-1beta. The lower IL-1beta group was defined as the patients with serum IL-1beta level less than median. And the higher IL-1beta group was defined as the patients with serum IL-1beta level more than median.

\section{Statistical analyses}

Statistical analyses of the clinical and biomedical parameters were performed using SPSS ver. 22.0 software (SPSS Inc., Chicago, IL, USA). The data distributions were assessed using the Kolmogorov-Smirnov test. The data are presented as means \pm standard error of the mean (SEM). Normally distributed data examined by the two-sample independent Student's $t$-test. Nonnormally distributed data examined using the nonparametric Mann-Whitney $U$-test or Kruskal-Wallis analysis of variance (ANOVA).
Results for categorical variables are reported as percentages and were examined by the chi-square test. Simple linear and partial correlation coefficients were calculated for the relationships between the F-score and the anthropometric parameters. Subsequently, the significant parameters were used as input in a multivariate regression model to identify the independent associations with F-score. Odds ratios determined by polychotomous logistic regression analysis were used to describe the associations between the parameters and each of four categories (low CVD and intermediate to high CVD risk groups in the non-DM and DM groups). A two-sided $\mathrm{P}$ value $<0.05$ was considered significant.

\section{Results}

\section{Clinical characteristics}

A total of 110 subjects were enrolled in this study. The study participants were divided into the non-DM $(\mathrm{n}=52)$ and DM ( $\mathrm{n}=58$ patients newly diagnosed, drug-naïve T2DM) groups. The clinical characteristics of the subjects are presented in Table 1. Age and sex were similar, but smoking status was significantly different between the two groups. Hypertension medication use and diastolic BP were similar between the two groups, but systolic BP was higher in the DM than in the non-DM group. BMI, HbA1 $1_{C}$, fasting plasma glucose (FPG), 2-hour post-load plasma glucose after $75 \mathrm{~g}$ OGTT (2-h PG), fasting insulin, fasting C-peptide, HOMA-IR, total cholesterol, LDL cholesterol, triglyceride (TG) and F-scores were significantly higher $(\mathrm{P}<0.05)$, and HOMA-beta and HDL-cholesterol were significantly lower, in the DM group than in the non-DM group $(\mathrm{P}<0.05)$. Interestingly, apoprotein (apo) A and $\mathrm{B}$, high sensitivity $\mathrm{C}$-reactive protein (hs-CRP) and IL-1beta levels were not different between the groups.

\section{Correlation between the serum IL-1beta level and F-score}

We investigated the relationship between the F-score and anthropometric and laboratory measures excluding those used to calculate the F-score. Spearman's correlation analysis revealed that the F-score was positively correlated with BMI, $\mathrm{HbAl}_{\mathrm{C}}, \mathrm{FPG}$, fasting C-peptide, HOMA-IR, TG, apo B, and IL-1beta but negatively correlated with apo A in all subjects (Figure $2 A$ and Table 2). We also calculated the correlation after adjusting in three conditions; (I) BMI; (II) $\mathrm{HbA1}_{\mathrm{C}}$ and fasting plasma glucose, 2-h PG; (III) LDL 
Table 1 Clinical and laboratory characteristics of study subjects

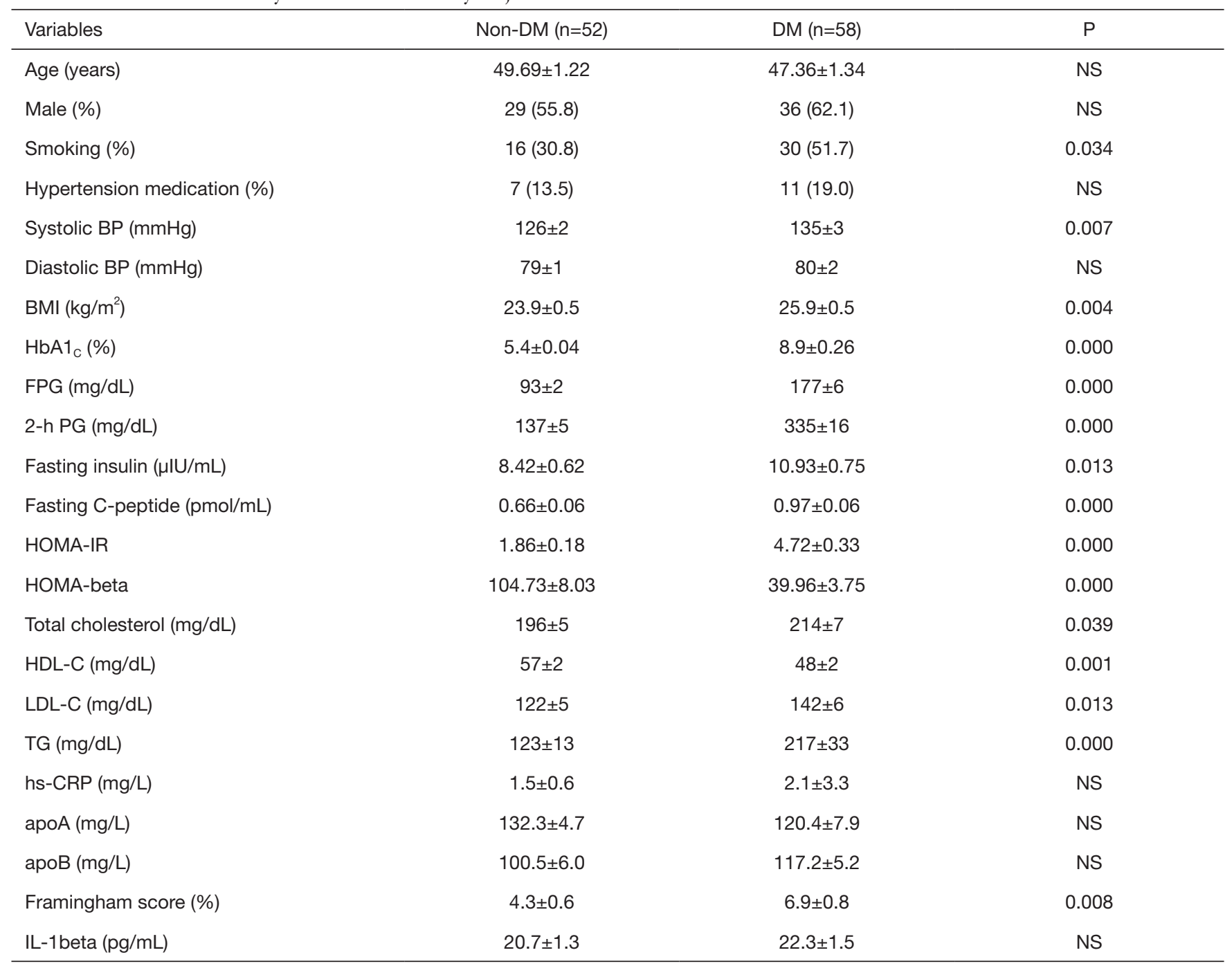

Data are expressed as the mean \pm SEM, or $\mathrm{n}(\%)$. $\mathrm{P}$ value was calculated by independent Student $t$ test or the Mann-Whitney $\mathrm{U}$ test. BP, blood pressure; BMl, body mass index; HbA1c, hemoglobin A1c; FPG, fasting plasma glucose; 2-h PG, 2-hour post-load plasma glucose after $75 \mathrm{~g}$ oral glucose tolerance test; HOMA-IR, homeostasis model assessment-insulin resistance; HDL-C, high density lipoprotein cholesterol; LDL-C, low density lipoprotein cholesterol; TG, Triglyceride; hs-CRP, highly sensitive C-reactive protein; IL-1beta, interleukin-1beta.

cholesterol and triglyceride. After adjusting for BMI, FPG, fasting C-peptide, TG and IL-1beta remained significantly associated with the F-score. After adjusting for $\mathrm{HbA1}_{\mathrm{C}}$, FPG and 2-h PG Fasting C-peptide, HOMA-IR and IL-1beta remained significantly associated and hs-CRP showed newly association with the F-score. After adjusting for LDL cholesterol and TG, fasting C-peptide and IL-1beta remained significantly associated with the F-score (Table 2).

To identify whether the non-DM and DM groups showed similar correlation patterns in all subjects, we also performed a Spearman's correlation analysis in each group. F-score in the non-DM group was positively correlated with fasting C-peptide $(\mathrm{r}=0.451, \mathrm{P}=0.011)$ and TG $(\mathrm{r}=0.333, \mathrm{P}=0.016)$ but not with IL-1beta $(\mathrm{r}=0.096, \mathrm{P}=0.496)$ (Figure 2B). After adjusting in above conditions, fasting $\mathrm{C}$-peptide remained positively association and hs-CRP showed newly association with the F-score: (I) fasting C-peptide $(\mathrm{r}=0.442, \mathrm{P}=0.016)$ and hs-CRP $(\mathrm{r}=0.586, \mathrm{P}=0.003)$, (II) fasting C-peptide ( $\mathrm{r}=0.387, \mathrm{P}=0.046)$ and hs-CRP $(\mathrm{r}=0.590$, $\mathrm{P}=0.005)$, (III) fasting $\mathrm{C}$-peptide $(\mathrm{r}=0.423, \mathrm{P}=0.022)$ and 

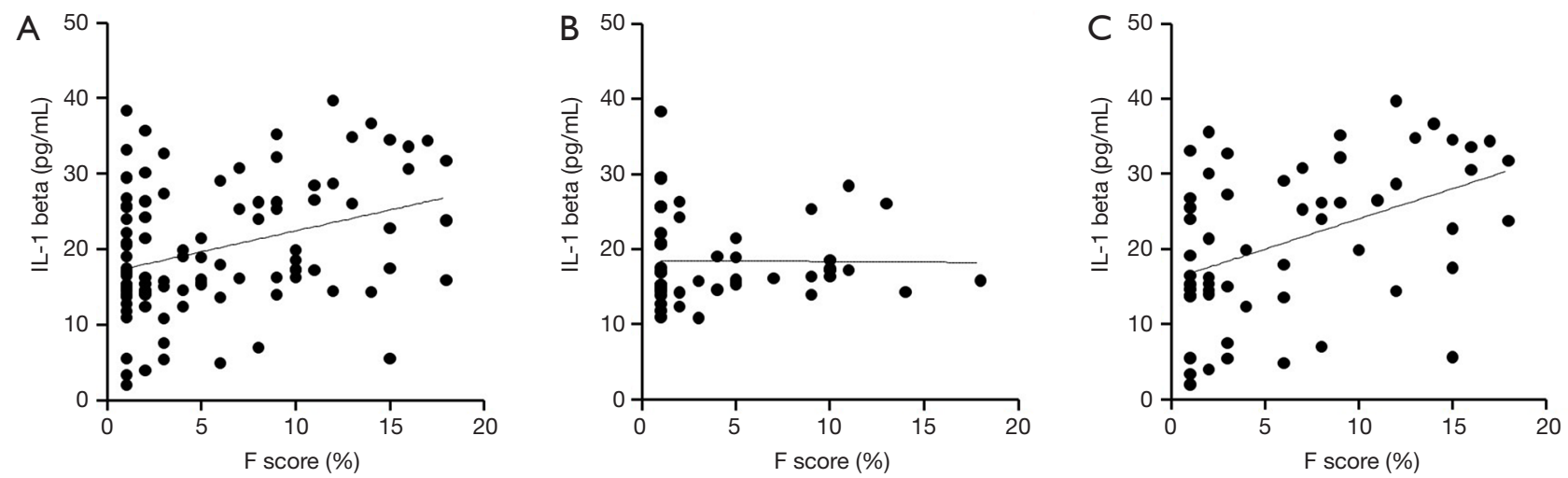

Figure 2 The linear correlation pattern between Framingham CVD risk score and serum IL-1beta level. (A) Correlation in total subjects. This result indicates a significantly positive correlation $(r=0.314, \mathrm{P}=0.002)$ (B) Correlation in non-DM group. This result indicates no significant correlation $(r=0.086, P=0.563)$. (C) Correlation in $\mathrm{DM}$ group. This result indicates a significantly positive correlation ( $\mathrm{r}=0.482$, $\mathrm{P}<0.001)$.

Table 2 Partial correlation analysis of variables associated with Framingham CVD risk score

\begin{tabular}{|c|c|c|c|c|c|c|c|c|}
\hline Variables & \multicolumn{4}{|c|}{ All study subjects } & \multicolumn{4}{|c|}{ DM group } \\
\hline BMI $\left(\mathrm{kg} / \mathrm{m}^{2}\right)$ & $0.222^{*}$ & & 0.162 & 0.111 & 0.093 & & -0.077 & 0.076 \\
\hline $\mathrm{FPG}(\mathrm{mg} / \mathrm{dL})$ & $0.282^{\star \star}$ & $0.226^{*}$ & & 0.157 & 0.081 & 0.073 & & -0.003 \\
\hline 2-h PG & 0.141 & 0.018 & & -0.035 & -0.103 & -0.223 & & \\
\hline Fasting insulin ( $\mu \mathrm{lU} / \mathrm{mL})$ & 0.130 & 0.089 & 0.132 & 0.112 & -0.002 & 0.053 & 0.121 & 0.072 \\
\hline Fasting C-peptide (pmol/mL) & $0.359^{\star *}$ & $0.362^{\star *}$ & $0.319^{*}$ & $0.363^{\star \star}$ & 0.189 & $0.297^{\star}$ & 0.180 & $0.319^{*}$ \\
\hline LDL-C (mg/dL) & 0.092 & -0.048 & -0.019 & & -0.113 & -0.216 & -0.050 & -0.012 \\
\hline $\mathrm{TG}(\mathrm{mg} / \mathrm{dL})$ & $0.281^{\star *}$ & $0.287^{*}$ & 0.142 & & 0.124 & $0.289^{*}$ & -0.058 & \\
\hline hs-CRP (mg/L) & 0.195 & 0.147 & $0.488^{* *}$ & 0.175 & -0.048 & -0.045 & 0.104 & \\
\hline apoA (mg/L) & $-0.412^{\star *}$ & -0.270 & -0.155 & -0.282 & -0.326 & -0.274 & -0.021 & -0.242 \\
\hline apoB (mg/L) & $0.374^{*}$ & 0.145 & 0.199 & 0.138 & 0.249 & 0.020 & 0.197 & 0.042 \\
\hline IL-1beta (pg/mL) & $0.314^{\star \star}$ & $0.331^{\star \star \star}$ & $0.264^{*}$ & $0.302^{\star \star}$ & $0.482^{\star \star \star}$ & $0.520^{\star \star \star}$ & $0.547^{\star \star}$ & $0.480^{\star \star \star}$ \\
\hline
\end{tabular}

$\mathrm{r}$ value was calculated by the simple linear and partial rank correlation analysis. Partial correlation was adjusted with BMI, $\mathrm{HbA} 1_{\mathrm{C}}$, and $\mathrm{FPG}$. *, $\mathrm{P}<0.05$; ${ }^{* \star}, \mathrm{P}<0.01$; ${ }^{* \star}, \mathrm{P}<0.001$. BMI, body mass index; HbA1c, hemoglobin A1c; FPG, fasting plasma glucose; 2-h PG, 2-hour post-load plasma glucose after $75 \mathrm{~g}$ oral glucose tolerance test; HOMA-IR, homeostasis model assessment-insulin resistance; LDL-C, low density lipoprotein cholesterol; TG, Triglyceride; hs-CRP, highly sensitive C-reactive protein; IL-1 $\beta$, interleukin-1 $\beta$. 
hs-CRP ( $\mathrm{r}=0.580, \mathrm{P}=0.004)$. However, IL-1beta was not association with the F-score after adjusting. The F-score in the DM group only was positively correlated with IL-1beta before adjusting (Figure $2 \mathrm{C}$ and Table 2). The correlation between IL-1beta and F-score remained significant after adjusting in above conditions (Table 2). After adjusting for $\mathrm{BMI}$, fasting C-peptide and TG were positively correlated with the F-score. After adjusting for LDL cholesterol and TG, fasting C-peptide was positively correlated with the F-score. To estimate the independent contribution of F-score to IL-1beta in the DM group, we performed multivariate regression analyses using two models. The first model included the glycemic parameters $\left(\mathrm{HbAl}_{\mathrm{C}}, \mathrm{FPG}\right.$, and 2-h PG), and the second model included lipid parameters (LDL-cholesterol, triglycerides, apoA, and apoB). Both models revealed a significant correlation between IL-1beta and the F-score $\left(R^{2}=0.150, \beta=0.387, P=0.022\right.$ and $R^{2}=0.324$, $\beta=0.569, P=0.021)$. An elevated serum IL-1 beta level increased the odds of intermediate to high CVD risk only in the presence of diabetes (odds ratio, 1.125; $\mathrm{P}=0.002$ ), indicating that an increased IL-1beta level in patients with T2DM may affect the risk of CVD.

\section{Factor changed according to serum IL-1beta level}

To identify the independent factors with IL-1beta, we also performed a Spearman's correlation analysis in all subjects and DM group. IL-1beta showed only positive correlation with $\mathrm{F}$-score in all subjects $(\mathrm{r}=0.314, \mathrm{P}=0.001)$ and $\mathrm{DM}$ group $(\mathrm{r}=0.482, \mathrm{P}<0.001)$. In all subjects, higher IL-1beta group showed significantly higher serum IL-1beta $(13.4 \pm 0.6$ vs. $29.6 \pm 1.2 \mathrm{pg} / \mathrm{mL}, \mathrm{P}<0.001), \mathrm{F}$-score $(4.4 \% \pm 0.6 \%$ vs. $7.1 \% \pm 0.8 \%, \mathrm{P}=0.007)$, and HOMA-IR $(2.73 \pm 0.26$ vs. $3.96 \pm 0.38, \mathrm{P}=0.009)$, but no significant difference in other factors. In DM group, higher IL-1beta group showed significantly higher serum IL-1beta $(11.3 \pm 1.1 v s$. $30.0 \pm 1.2 \mathrm{pg} / \mathrm{mL}, \mathrm{P}<0.001)$ and $\mathrm{F}$-score $(4.1 \% \pm 0.9 \%$ vs. $8.9 \% \pm 1.0 \%, \mathrm{P}=0.001)$, but no significant difference in other factors including HOMA-IR.

\section{Changes in the serum IL-1beta level according to CVD risk}

Because IL-1beta is a key player in cardiovascular risk $(18,21,27)$, we also stratified the non-DM and DM groups according to their CVD risk: low CVD risk (F-score $<5 \%$ ) and intermediate to high CVD risk (F-score $\geq 10 \%$ ) (12). As shown in Table 3, all subjects with an intermediate to high CVD risk were significantly older and had higher fasting
C-peptide levels compared with those with a low CVD risk $(\mathrm{P}<0.05)$. Subjects in the DM group with intermediate to high CVD risk had significantly higher serum IL-1beta levels than did those with low CVD risk $(17.3 \pm 9.4 v$ s. 29.6 $\pm 11.4, \mathrm{P}<0.001$ ), whereas no difference between those with low and those with intermediate to high CVD risk [18.8 (14.4-22.7) vs. 19.1 (16.1-22.3), $\mathrm{P}=0.525$ ] was detected in the non-DM group. Serum IL-1beta levels in the non-DM subjects with low CVD risk, the non-DM subjects with intermediate to high CVD risk, the DM subjects with low CVD risk, and the DM subjects with intermediate to high CVD risk were significantly different $(\mathrm{P}<0.001)$ (Figure 3). A post-hoc comparison revealed significantly higher IL1beta levels in the DM group with intermediate to high CVD risk than in the other groups.

Obesity has been well known as an independent risk factor for CVD, but is not included in the F-score calculations. Therefore, we compared serum IL-1beta levels according to the BMI in the DM subjects. So, we stratified the non-obesity and obesity groups according to the BMI: healthy weight (BMI $<25)$, overweight $(25 \leq \mathrm{BMI}<30)$, obesity (BMI $\geq 30$ ). We confirmed that IL-1beta (mean \pm SEM) showed no significant difference between two groups: (I) healthy weight (BMI $<25, \mathrm{n}=24)$ vs. obesity (BMI $\geq 30$, $\mathrm{n}=11), 23.9 \pm 2.4$ vs. $22.1 \pm 2.9(\mathrm{P}=0.647)$, (II) healthy weight $(\mathrm{BMI}<25, \mathrm{n}=24) v s$. overweight and more (BMI $\geq 25, \mathrm{n}=34)$, $23.9 \pm 2.4$ vs. 21.1 $\pm 1.9(\mathrm{P}=0.352)$, (III) non-obesity (BMI $<30$, $\mathrm{n}=47)$ vs. obesity $(\mathrm{BMI} \geq 30, \mathrm{n}=11), 22.3 \pm 1.7$ vs. $22.1 \pm 2.9$ $(\mathrm{P}=0.952)$.

\section{Changes in serum IL-1beta levels according to smoking bistory}

Because smoking is one of the most important risk factors associated with the pathogenesis of atherosclerosis, we stratified the non-DM and DM groups according to smoking history. As shown in Table 4, most of the smokers were male and had higher F-scores in both groups. However, the IL-1beta level was not different between smokers and nonsmokers in the non-DM group but was higher in smokers than in non-smokers in the DM group. IL-1beta levels in the non-DM subjects without a smoking history, the non-DM subjects with a smoking history, the DM subjects without a smoking history, and the DM subjects with a smoking history were significantly different $(\mathrm{P}=0.007)$. A post-hoc comparison revealed that patients in the DM group with a smoking history had significantly higher IL-1beta levels than did those in the other groups 
Table 3 Clinical and laboratory characteristics of study subjects according to CVD risk

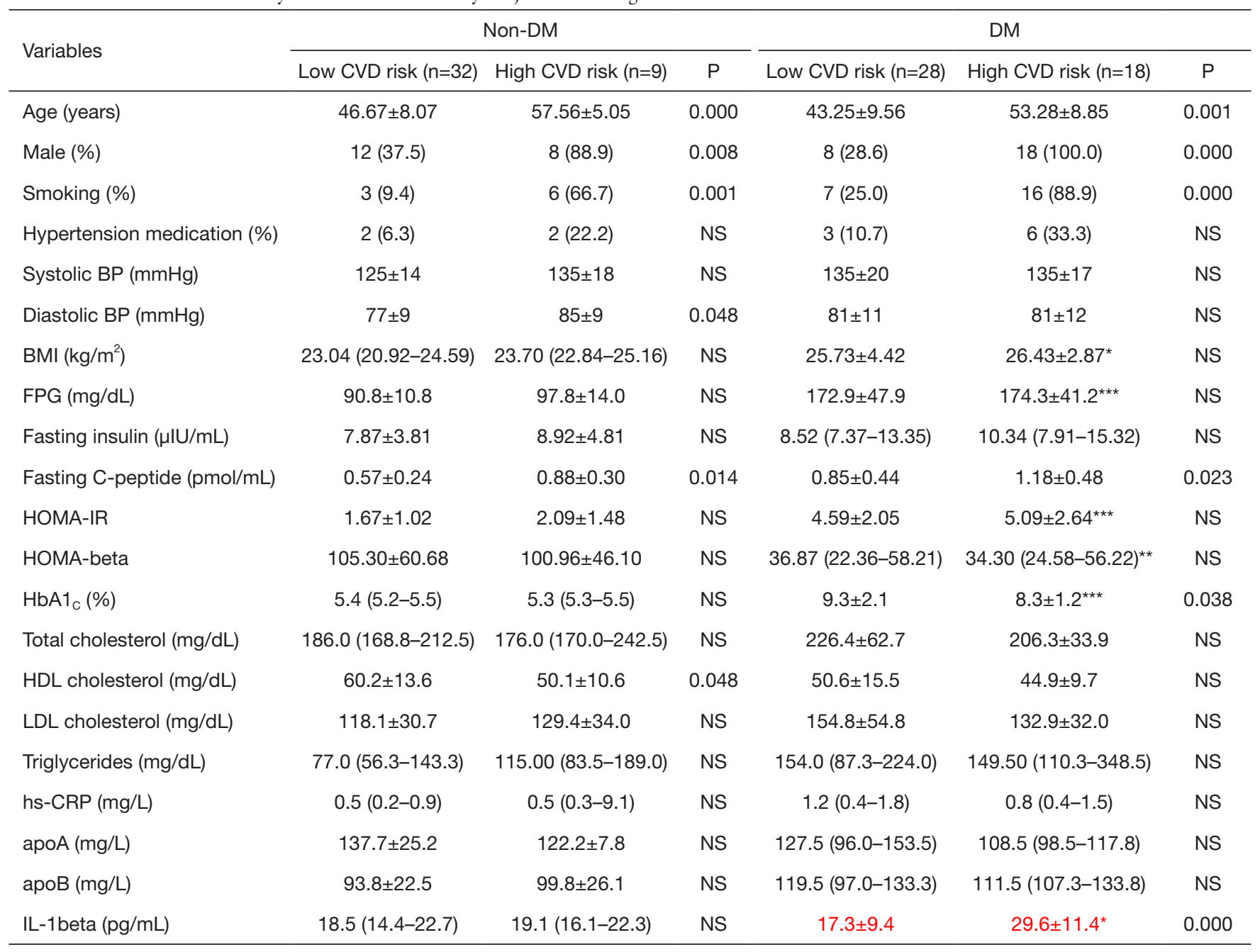

Data are expressed as the mean \pm SEM or $\mathrm{n}(\%)$. $\mathrm{P}$ value was calculated by independent Student $t$ test or the Mann-Whitney $\mathrm{U}$ test. * compared between Non-DM and DM with high CVD risk. * $\mathrm{P}<0.05$; ${ }^{* *}, \mathrm{P}<0.01$; and ${ }^{* *}, \mathrm{P}<0.001$. BP, blood pressure; BMI, body mass index; FPG, fasting plasma glucose; HOMA-IR, homeostasis model assessment-insulin resistance; HbA1c, hemoglobin A1c; HDL, high density lipoprotein; LDL, low density lipoprotein; hs-CRP, highly sensitive C-reactive protein; IL-1 $\beta$, interleukin-1 $\beta$.

(Figure 4). To identify which factors differed significantly in subjects with a smoking history between the non-DM and DM groups besides IL-1beta, we analyzed the parameters using the two-sample independent Student's $t$-test or the nonparametric Mann-Whitney $U$-test. As shown in Table 4, subjects in the non-DM and DM groups with a smoking history significantly differed in terms of BMI, FPG, fasting C-peptide, HOMA-IR, HOMA-beta, $\mathrm{HbA1}_{\mathrm{C}}$, and HDLcholesterol, which are distinct features of T2DM. These results demonstrate that smoking has a particularly strong influence on IL-1beta levels in patients with T2DM.

However, although smoking history in the DM group was very strong association with serum IL-1beta, the correlation between serum IL-1beta level and F-score in the DM group remained significant after adjusting for smoking history that is an important factor in the F-score calculation $(\mathrm{r}=0.459, \mathrm{P}<0.001)$.

\section{Discussion}

This is the first study to investigate the association between IL-1beta as a marker of activation of the NLRP3 inflammasome and CVD risk in patients with newly diagnosed, drug-naïve T2DM. We found a significant 


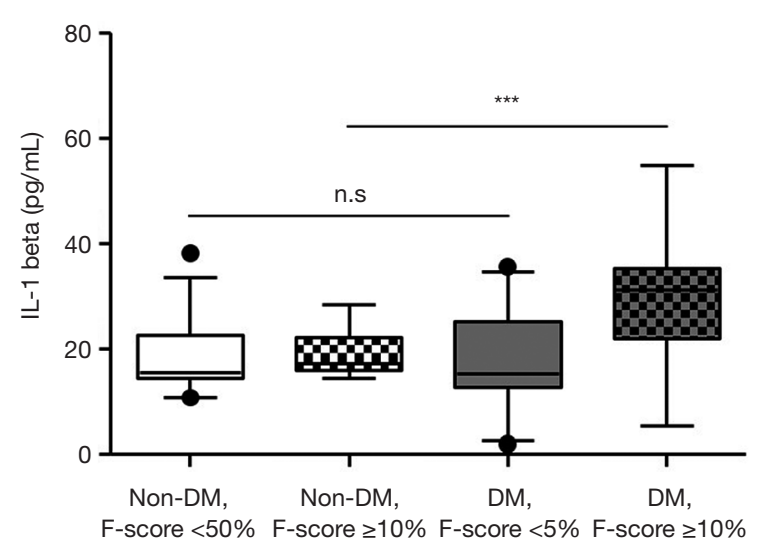

Figure 3 The serum IL-1beta level according to Framingham risk score. All Non-DM group and DM group with low CVD risk (Framingham CVD risk score $<5 \%$ ) have no significantly difference in serum IL-1beta level. DM group with intermediate to high CVD risk (Framingham CVD risk score $\geq 10 \%$ ) has significantly higher serum IL-1beta level than other groups. P value was calculated by Kruskal-Wallis ANOVA. n.s., not significant. ***, $\mathrm{P}<0.001$. F score; Framingham CVD risk score.

positive correlation between the serum inflammatory marker IL-1beta level and CVD risk calculated using the F-score only in patients with newly diagnosed, drug naïve T2DM (DM group) but not in subjects without T2DM (non-DM group). In addition, F-score in DM group had no correlation with another inflammatory marker, hsCRP. This is very interesting finding because hs-CRP is thought as an independent risk factor for cardiovascular disease and future diabetes. Our previous study showed that patients with newly diagnosed, drug-naïve diabetes have no significant difference in serum CRP levels compared to and subjects without diabetes, but had significantly increased mRNA and protein expression of NLRP3, required for IL1 beta synthesis, in monocyte-derived macrophages (22). Therefore, this study supported that IL-1beta in early diabetes is expressed earlier than CRP as an indicator of chronic inflammation, and the correlation between F-score and IL-1beta show only in DM group with sensitivity on inflammatory stimulation.

Although many studies have shown that inflammation plays an important role in the progression of T2DM. Some studies have reported that serum IL-1beta levels are not different between subjects with normal glucose tolerance and those with T2DM $(19,28,29)$, whereas other studies have reported that serum IL-1beta levels are higher in patients with T2DM than in those without T2DM $(22,30)$. These conflicting results suggest that serum IL-1beta levels in patients with T2DM may have been influenced by selecting patients who use anti-diabetic drugs or have progressing diabetic complications. In fact, our previous study showed that the anti-diabetic drug metformin inhibits secretion of IL-1beta from monocyte-derived macrophages in patients with diabetes (22). We found no difference in serum IL-1beta levels between the DM and non-DM group, although serum IL-1beta levels tended to be higher in the DM group than in the non-DM group $(\mathrm{P}=0.077)$.

T2DM can be diagnosed by the blood glucose level (23). However, the pathogenesis involves a great variety of genetic and environmental factors (31). Macrovascular complications, particularly CVD, can develop in subjects with prediabetes (32), indicating that the absolute glucose level could be a necessary, but not sufficient, condition for developing CVD. Therefore, it is very important to understand and investigate changes in body conditions caused by diabetes. We hypothesized that the proinflammatory cytokine IL-1beta represents CVD risk in patients with T2DM. Serum IL-1beta level increased significantly in the DM group with intermediate to high CVD risk, but no difference was found in either group with a low CVD risk. Various laboratory results differed between the DM and non-DM groups with intermediate to high CVD risk; the DM group exhibited obesity, hyperglycemia, insulin resistance, beta-cell dysfunction, and higher inflammatory cytokine levels. These factors are remarkable clinical features of diabetes and could be risk factors for developing CVD. However, IL-1beta was only correlated with the F-score. In the DM group, this relationship between IL-1beta and F-score was independent of obesity severity and hyperglycemia, suggesting that the development of CVD in patients with T2DM could be caused by inflammation rather than the absolute glucose level.

Smoking is a very important risk factor for inflammatory disorders, such as cancers, coronary heart disease, stroke, $\mathrm{DM}$, and chronic obstructive pulmonary disease (COPD) (33-38), although the effects of smoking are not fully understood. One study demonstrated that serum IL-1beta levels are increased in active smokers and are induced by the inflammatory response through production of reactive oxygen species and cyclooxygenase- 2 in endothelial cells (39). Another study demonstrated that smoking results in greater secretion of pro-inflammatory mediators, such as IL-1beta, in patients with COPD than in those 
Table 4 Clinical and laboratory characteristics of study subjects according to smoking history

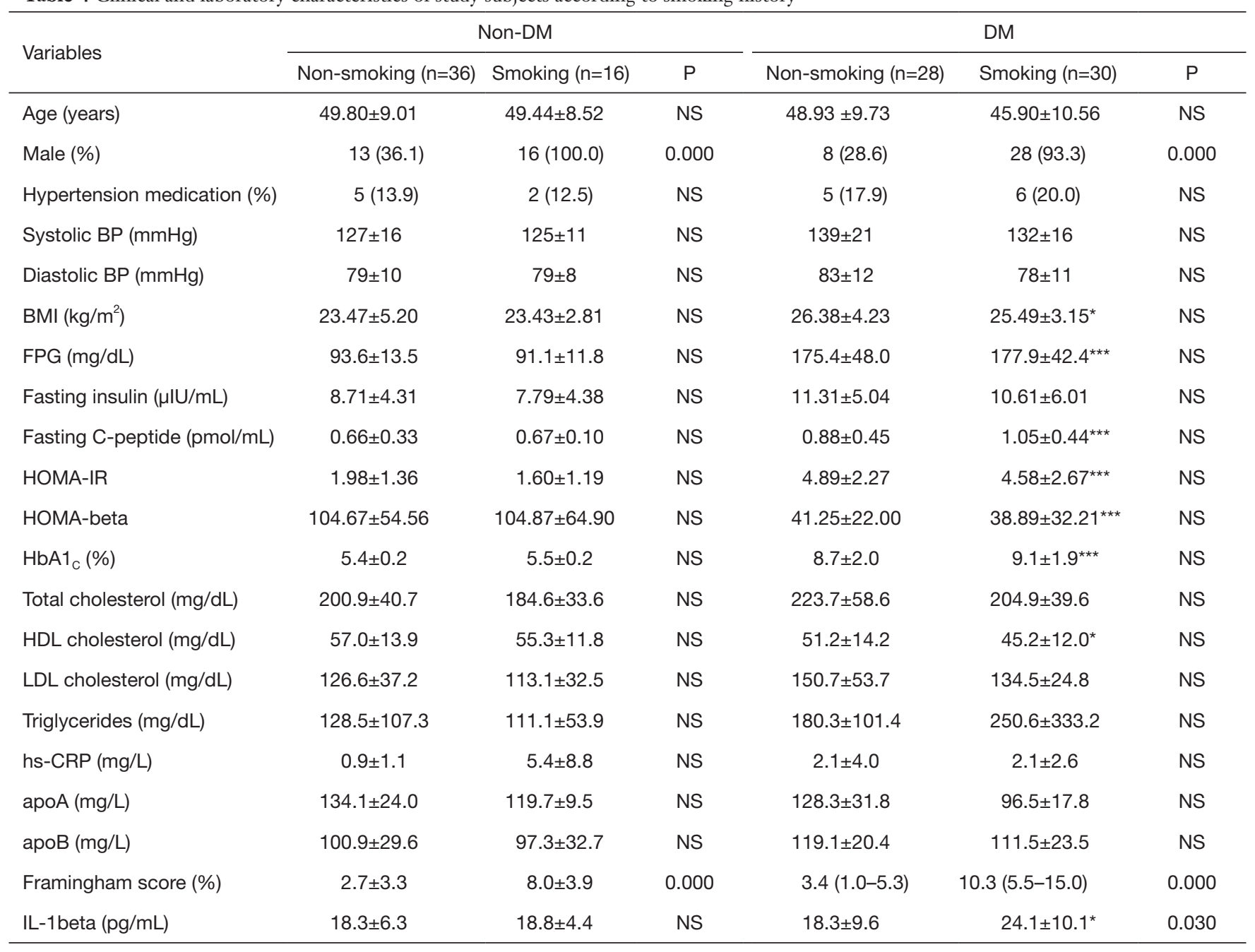

Data are expressed as the mean \pm SEM, or $\mathrm{n}(\%)$. $\mathrm{P}$ value was calculated by independent Student $t$ test or the Mann-Whitney $\mathrm{U}$ test. * compared between Non-DM and DM with smoking history. ${ }^{*}, \mathrm{P}<0.05$; ${ }^{* *}, \mathrm{P}<0.01$; and ${ }^{* \star *}, \mathrm{P}<0.001$. BP, blood pressure; BMI, body mass index; FPG, fasting plasma glucose; HOMA-IR, homeostasis model assessment-insulin resistance; HbA1c, hemoglobin A1c; HDL, high density lipoprotein; LDL, low density lipoprotein; hs-CRP, highly sensitive C-reactive protein; IL-1 $\beta$, interleukin-1 $\beta$.

without COPD (40-42). In other words, patients with COPD could have higher inflammatory susceptibility to smoking. Therefore, we analyzed the effects of smoking on serum IL-1beta levels in subjects with and without T2DM. Surprisingly, serum IL-1beta levels were increased only in patients in the DM group with a smoking history, suggesting that patients with DM could have greater susceptibility to the smoking-induced release of IL-1beta. Many studies have proposed that inflammatory conditions can be exacerbated and accelerated in patients with diabetes $(43,44)$. This hypothesis is supported by our results in which activation of the immune system in patients with T2DM was intensified by a stimulus, such as smoking, and could aggravate atherosclerosis. To determine whether some clinical factors between the DM and non-DM groups had effects on serum IL-1beta levels, we performed a subgroup analysis. Subjects with a smoking history in the DM and non-DM groups showed no differences in age, sex, SBP, or history of hypertension medication use, which were used to calculate the F-score. As expected, the F-score was not different between subjects in the DM and non-DM groups who smoked. These results indicate that the F-score may underestimate the effect of smoking which could provoke activation of the innate immune system in patients with 


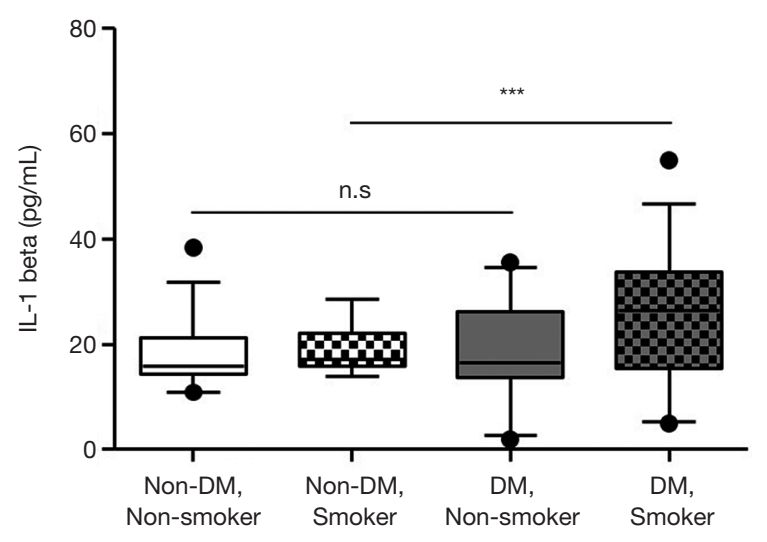

Figure 4 The serum IL-1beta level according to smoking history. All non-DM group and DM group with smoking have no significantly difference in serum IL-1beta level. DM group with smoking history has significantly higher serum IL-1beta level than other groups. P value was calculated by Kruskal-Wallis ANOVA; ns, not significant. ${ }^{* * *}, \mathrm{P}<0.001$.

\section{T2DM.}

In conclusion, serum IL-1beta levels may be related to CVD risk, particularly in patients with T2DM who smoke. Although we did not observe a difference in serum IL1 beta levels between the DM and non-DM groups, our results suggest that the serum IL-1beta level could be used to calculate the CVD risk in patients with T2DM. Further study is needed to investigate whether patients with T2DM and elevated serum IL-1beta levels have an increased incidence of CVD.

Several limitations should be mentioned for the present study. First, our study did not measure the waist circumference and waist-hip ratio. These are essential to identify phenotypes of diabetic patients with body weight and BMI. Although our results showed no correlation between IL-1beta and obesity represented by BMI, we could not conclude that IL-1beta was not correlation with the waist circumference and/or waist-hip ratio. Second, the present study was carried out in South Korean, where the incidence of obesity is low compared with Caucasians. Therefore, we could conclude that diabetic patients with severe obesity were not correlation between IL-1beta and obesity. Third, we did not exclude the hypertension in our study. Although we excluded the patients taking antihypertensive drug ARB from this study, some studies have reported that hypertension itself might increase serum IL1 beta levels. Therefore, our study might have the bias by hypertension. Fourth, this was cross-sectional study, and we could not conclude that serum IL-1beta levels in diabetic patients paly as an independent factor for CVD. Therefore, additional prospective studies on relationship between IL1 beta and CVD morbidity with a large sample size are required.

\section{Acknowledgments}

Funding: This work was supported by Chungnam National University Hospital Research Fund, 2018.

\section{Footnote}

Conflicts of Interest: The authors have no conflicts of interest to declare.

Ethical Statement: The authors are accountable for all aspects of the work in ensuring that questions related to the accuracy or integrity of any part of the work are appropriately investigated and resolved. This research protocol was approved by the Institutional Review Board of Chungnam National University Hospital (CNUH 1101-11), and written informed consent was provided by all participants.

Open Access Statement: This is an Open Access article distributed in accordance with the Creative Commons Attribution-NonCommercial-NoDerivs 4.0 International License (CC BY-NC-ND 4.0), which permits the noncommercial replication and distribution of the article with the strict proviso that no changes or edits are made and the original work is properly cited (including links to both the formal publication through the relevant DOI and the license). See: https://creativecommons.org/licenses/by-nc-nd/4.0/.

\section{References}

1. Moss SE, Klein R, Klein BE, et al. The association of glycemia and cause-specific mortality in a diabetic population. Arch Intern Med 1994;154:2473-9.

2. Andersson DK, Svardsudd K. Long-term glycemic control relates to mortality in type II diabetes. Diabetes Care 1995;18:1534-43.

3. Kuusisto J, Mykkanen L, Pyorala K, et al. NIDDM and its metabolic control predict coronary heart disease in elderly subjects. Diabetes 1994;43:960-7.

4. Silbernagel G, Grammer TB, Winkelmann BR, et al. Glycated hemoglobin predicts all-cause, cardiovascular, and cancer mortality in people without a history of 
diabetes undergoing coronary angiography. Diabetes Care 2011;34:1355-61.

5. Di Pino A, Scicali R, Calanna S, et al. Cardiovascular risk profile in subjects with prediabetes and new-onset type 2 diabetes identified by $\mathrm{HbA}(1 \mathrm{c})$ according to American Diabetes Association criteria. Diabetes Care 2014;37:1447-53.

6. Yudkin JS, Richter B. Intensive glucose control and cardiovascular outcomes. Lancet 2009;374:522; author reply 524.

7. Gaede P, Lund-Andersen H, Parving HH, et al. Effect of a multifactorial intervention on mortality in type 2 diabetes. N Engl J Med 2008;358:580-91.

8. Sattar N. Revisiting the links between glycaemia, diabetes and cardiovascular disease. Diabetologia 2013;56:686-95.

9. Kannel WB, McGee DL. Diabetes and cardiovascular disease. The Framingham study. JAMA 1979;241:2035-8.

10. Stamler J, Vaccaro O, Neaton JD, et al. Diabetes, other risk factors, and 12-yr cardiovascular mortality for men screened in the Multiple Risk Factor Intervention Trial. Diabetes Care 1993;16:434-44.

11. D'Agostino RB, Sr., Vasan RS, Pencina MJ, et al. General cardiovascular risk profile for use in primary care: the Framingham Heart Study. Circulation 2008;117:743-53.

12. Grundy SM, Pasternak R, Greenland P, et al. AHA/ ACC scientific statement: Assessment of cardiovascular risk by use of multiple-risk-factor assessment equations: a statement for healthcare professionals from the American Heart Association and the American College of Cardiology. J Am Coll Cardiol 1999;34:1348-59.

13. Coleman RL, Stevens RJ, Retnakaran R, et al. Framingham, SCORE, and DECODE risk equations do not provide reliable cardiovascular risk estimates in type 2 diabetes. Diabetes Care 2007;30:1292-3.

14. Simmons RK, Coleman RL, Price HC, et al. Performance of the UK Prospective Diabetes Study Risk Engine and the Framingham Risk Equations in Estimating Cardiovascular Disease in the EPIC- Norfolk Cohort. Diabetes Care 2009;32:708-13.

15. Jee SH, Jang Y, Oh DJ, et al. A coronary heart disease prediction model: the Korean Heart Study. BMJ Open 2014;4:e005025.

16. Won KB, Chang HJ, Park SH, et al. High serum advanced glycation end-products predict coronary artery disease irrespective of arterial stiffness in diabetic patients. Korean Circ J 2012;42:335-40.

17. Nin JW, Jorsal A, Ferreira I, et al. Higher plasma soluble Receptor for Advanced Glycation End Products (sRAGE) levels are associated with incident cardiovascular disease and all-cause mortality in type 1 diabetes: a 12 -year followup study. Diabetes 2010;59:2027-32.

18. Ozeren A, Aydin M, Tokac M, et al. Levels of serum IL1beta, IL-2, IL-8 and tumor necrosis factor-alpha in patients with unstable angina pectoris. Mediators Inflamm 2003;12:361-5.

19. Spranger J, Kroke A, Mohlig M, et al. Inflammatory cytokines and the risk to develop type 2 diabetes: results of the prospective population-based European Prospective Investigation into Cancer and Nutrition (EPIC)-Potsdam Study. Diabetes 2003;52:812-7.

20. Esposito K, Nappo F, Marfella R, et al. Inflammatory cytokine concentrations are acutely increased by hyperglycemia in humans: role of oxidative stress. Circulation 2002;106:2067-72.

21. Merhi-Soussi F, Kwak BR, Magne D, et al. Interleukin-1 plays a major role in vascular inflammation and atherosclerosis in male apolipoprotein E-knockout mice. Cardiovasc Res 2005;66:583-93.

22. Lee HM, Kim JJ, Kim HJ, et al. Upregulated NLRP3 inflammasome activation in patients with type 2 diabetes. Diabetes 2013;62:194-204.

23. American Diabetes Association. (2) Classification and diagnosis of diabetes. Diabetes Care 2015;38 Suppl:S8-S16.

24. Mosca A, Goodall I, Hoshino T, et al. Global standardization of glycated hemoglobin measurement: the position of the IFCC Working Group. Clin Chem Lab Med 2007;45:1077-80.

25. Matthews DR, Hosker JP, Rudenski AS, et al. Homeostasis model assessment: insulin resistance and beta-cell function from fasting plasma glucose and insulin concentrations in man. Diabetologia 1985;28:412-9.

26. Lee SH, Lee BW, Won HK, et al. Postprandial Triglyceride Is Associated with Fasting Triglyceride and HOMA-IR in Korean Subjects with Type 2 Diabetes. Diabetes Metab J 2011;35:404-10.

27. Chamberlain J, Francis S, Brookes Z, et al. Interleukin-1 regulates multiple atherogenic mechanisms in response to fat feeding. PLoS One 2009;4:e5073.

28. Morteza A, Nakhjavani M, Ghadiri-Anari A, et al. Serum interleukin-1 and interleukin-6 are correlated neither with oxidized low density lipoprotein, nor with lowgrade inflammation in patients with type 2 diabetes. Eur Cytokine Netw 2011;22:107-12.

29. Marques-Vidal P, Schmid R, Bochud M, et al. Adipocytokines, hepatic and inflammatory biomarkers and incidence of type 2 diabetes. the CoLaus study. PLoS One 
2012;7:e51768.

30. Dasu MR, Devaraj S, Park S, et al. Increased toll-like receptor (TLR) activation and TLR ligands in recently diagnosed type 2 diabetic subjects. Diabetes Care 2010;33:861-8.

31. Kahn SE, Cooper ME, Del Prato S. Pathophysiology and treatment of type 2 diabetes: perspectives on the past, present, and future. Lancet 2014;383:1068-83.

32. Dagogo-Jack S. Primary prevention of cardiovascular disease in pre-diabetes: the glass is half full and half empty. Diabetes Care 2005;28:971-2.

33. Taghizadeh N, Vonk JM, Boezen HM. Lifetime Smoking History and Cause-Specific Mortality in a Cohort Study with 43 Years of Follow-Up. PLoS One 2016;11:e0153310.

34. Chang CM, Corey CG, Rostron BL, et al. Systematic review of cigar smoking and all cause and smoking related mortality. BMC Public Health 2015;15:390.

35. Ockene IS, Miller NH. Cigarette smoking, cardiovascular disease, and stroke: a statement for healthcare professionals from the American Heart Association. American Heart Association Task Force on Risk Reduction. Circulation 1997;96:3243-7.

36. Ambrose JA, Barua RS. The pathophysiology of cigarette smoking and cardiovascular disease: an update. J Am Coll Cardiol 2004;43:1731-7.

37. Chang SA. Smoking and type 2 diabetes mellitus. Diabetes Metab J 2012;36:399-403.

Cite this article as: Joung KH, Kim JM, Choung S, Lee JH, Kim HJ, Ku BJ. Association between IL-1beta and cardiovascular disease risk in patients with newly diagnosed, drug-naïve type 2 diabetes mellitus: a cross-sectional study. Ann Transl Med 2020;8(5):225. doi: 10.21037/atm.2020.01.17
38. Haire-Joshu D, Glasgow RE, Tibbs TL. Smoking and diabetes. Diabetes Care 2004;27 Suppl 1:S74-5.

39. Barbieri SS, Zacchi E, Amadio P, et al. Cytokines present in smokers' serum interact with smoke components to enhance endothelial dysfunction. Cardiovasc Res 2011;90:475-83.

40. Pauwels NS, Bracke KR, Dupont LL, et al. Role of IL1alpha and the Nlrp3/caspase-1/IL-1beta axis in cigarette smoke-induced pulmonary inflammation and COPD. Eur Respir J 2011;38:1019-28.

41. Rusznak C, Mills PR, Devalia JL, et al. Effect of cigarette smoke on the permeability and IL-1beta and sICAM-1 release from cultured human bronchial epithelial cells of never-smokers, smokers, and patients with chronic obstructive pulmonary disease. Am J Respir Cell Mol Biol 2000;23:530-6.

42. Lo Tam Loi AT, Hoonhorst SJ, Franciosi L, et al. Acute and chronic inflammatory responses induced by smoking in individuals susceptible and non-susceptible to development of COPD: from specific disease phenotyping towards novel therapy. Protocol of a cross-sectional study. BMJ Open 2013. doi: 10.1136/bmjopen-2012-002178.

43. Pickup JC, Crook MA. Is type II diabetes mellitus a disease of the innate immune system? Diabetologia 1998;41:1241-8.

44. Donath MY, Shoelson SE. Type 2 diabetes as an inflammatory disease. Nat Rev Immunol 2011;11:98-107. 